\title{
Gebelik Döneminde Çiftler Arası Uyum ve Prenatal Bağlanma Arasındaki Illişki
}

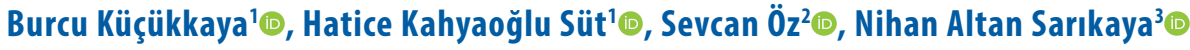

${ }^{1}$ Trakya Üniversitesi Sağlık Bilimleri Fakültesi, Hemşirelik Bölümü Kadın Sağlığı ve Hastalıkları Hemşireliği Anabilim Dalı, Edirne, Türkiye Ege Üniversitesi Hemşirelik Fakültesi, Ruh Sağlığı ve Hastalıkları Hemşireliği Anabilim Dalı, İzmir, Türkiye ${ }^{3}$ Trakya Üniversitesi Sağlık Bilimleri Fakültesi, Hemşirelik Bölümü Ruh Sağlığı ve Psikiyatri Hemşireliği Anabilim Dalı, Edirne, Türkiye

Burcu Küçükkaya, Arş. Gör. Uzm. Hatice Kahyaoğlu Süt, Doç. Dr. Sevcan Öz, Arş. Gör. Uzm. Nihan Altan Sarıkaya, Dr. Öğr. Üyesi

İletişim:

Arş. Gör. Uzm. Burcu Küçükkaya

Trakya Üniversitesi Sağlık Bilimleri Fakültesi, Hemşirelik Bölümü Kadın Sağı̆̆ı ve Hastalıkları Hemşireliği Anabilim Dalı, Edirne, Türkiye Tel: +9028421330 42 / 1026 E-Posta: burcukucukkaya1992@gmail.com

Gönderilme Tarihi : 27 Mayıs 2018 Revizyon Tarihi : : 13 Eylül 2018 Kabul Tarihi $\quad$ : 14 Eylül 2018
ÖZET

Amaç: Çalışmamızda, gebelik döneminde çiftler arası uyum ve prenatal bağlanma arasındaki ilişkiyi incelemek amaçlanmıştır.

Hastalar ve Yöntemler: Kesitsel tipteki bu çalışma Ocak-Mart 2018 tarihleri arasında bir üniversite hastanesinin kadın hastaIıkları-doğum polikliniğine başvuran n=195 gebe üzerinde yürütülmüştür. Araştırma verileri, "Anket Formu”, "ç̧iftler Uyum Ölçeği (ÇÜ))" ve "Prenatal Bağlanma Envanteri (PBE)" kullanılarak toplanmıştır.

Bulgular: Gebelerin yaş ortalaması $29.5 \pm 6.3$, eşlerinin yaş ortalaması $32.2 \pm 7.2$ 'tür. Gebelerin $\% 71,1$ 'inin tanışarak evlendiği ve evlilik süresi ortalamalarının $7.1 \pm 6.4$ olduğu bulunmuştur. Gebelerin $\% 49,2$ 'sinin 3 . trimesterde olduğu, $\% 71,6$ 'sının planlı gebelik yaşadığı belirlenmiştir. Gebelik sürecinde, gebelerin $\% 83,8^{\prime}$ inin duygusal destek aldığı, $\% 77,7$ 'sinin eşten ve $\% 74,1$ 'nin aileden duygusal destek aldığı saptanmıştır.

Gebelerin ÇUÖ puan ortalamasının $91,7 \pm 32,3$, PBE puan ortalamasııın ise $64,9 \pm 21,2$ olduğu saptanırken, ölçekler arasında pozitif yönde anlamlı bir ilişki olduğu bulunmuştur $(p<0,001)$. Tanışarak evlenen, planlı gebelik yaşayan, duygusal ya da fiziksel yönden destek alanların ÇUÖ ve PBE puan ortalamaları arasında pozitif yönde anlamlı ilişki olduğu belirlenmiştir $(p<0,001)$.

Sonuç: Gebelerin çift uyumu arttıkça prenatal bağlanma da artmaktadır. Tanışarak evlenen, planlı gebelik yaşayan, duygusal ya da fiziksel yönden destek alan gebelerin çift uyumu ve prenatal bağlanması daha yüksektir.

Anahtar sözcükler: Çift uyumu, gebelik, prenatal bağlanma

\section{THE RELATIONSHIP BETWEEN DYADIC ADJUSTMENT AND PRENATAL ATTACHMENT IN PREGNANCY}

\section{ABSTRACT}

Objectives: This study aims to investigate the relationship between dyadic adjustment and prenatal attachment in pregnancy.

Patients and Methods: This cross-sectional study was conducted on 195 women who applied to outpatient clinics of gynecology-obstetrics departments in a university hospital in Edirne, Turkey. Data were collected using a Survey Form, Dyadic Adjustment Scale (DAS) and Prenatal Attachment Inventory (PAI).

Results: Average age was found as $29.5 \pm 6.3$ in pregnants and $32.2 \pm 7.2$ in their husbands. 0 the 195 pregnants, $71.1 \%$ are married to each other, and the average marriage year was $7.1 \pm 6.4$.

Of the pregnants, $49.2 \%$ was in the third trimester, and $71.6 \%$ was planned pregnancy. The emotional support rate during pregnancy was found as $83.8 \%$, and of which $77.7 \%$ from spouses and $74.1 \%$ from the family. The mean DAS score was $91,7 \pm 32,3$, and the mean PAl score was $64,9 \pm 21,2$. There was a positive correlation between DAS scores and PAI scores of pregnant women $(r=0,8 ; p<0,001)$. Significantly higher DAS and PAI scores were found among pregnants who made love and were married?! $(p<0,001)$, planned pregnancy $(p=0,004)$, receiving emotional or physical support $(p<0,001)$.

Conclusion: When the dyadic adjustment increases among couples, prenatal attachment increases, too. Dyadic adjustment and prenatal attachment are higher among pregnants who made love and were married?!, planned pregnancy, receiving emotional or physical support.

Keywords: Dyadic adjustment, pregnancy, prenatal attachment 
G ebelik, doğurganlık dönemindeki her kadının yaşadığı, doğum ve annelik dönemine geçiş ile birlikte yeni bir benlik anlayışına ulaşmak için yeniden yapılanma hedeflerini, davranışlarını ve sorumluluklarını kapsayan karmaşık bilişsel, duyuşsal ve davranışsal değişiklikleri içeren fizyolojik bir olaydır. Bu dönemi, kadın yaşamında değişiklik ve yeni rollere uyum gerektiren bir kriz dönemi olarak görmek de mümkündür $(1,2)$. Gelişimsel bir kriz ya da kritik bir dönem olarak değerlendirilen bu dönemin, kadın yaşamındaki yeri oldukça önemlidir (3). Bu önemli dönemde çiftler arası uyum ve prenatal bağlanma, gebeliğin sağlıklı olarak sürmesinde önemli yere sahiptir (4).

Çiftler arası uyum, çiftlerin uyumlu birlikteliklerinin sonucu olarak evlilik hayatlarında yaşadıkları memnuniyet ve mutluluk olarak tanımlanmıştır. Bu tanımlamayla, çiftlerden her ikisinin de ilişki sürdürebilme kapasiteleri evlilik uyumunu sağlamak için önemli hale gelmektedir (5). Evlilik uyumu ile ilgili yapılan araştırmalardan, cinsiyet, çocuk sahibi olma durumu, evlilik biçimi, evlilik süresi, yaş, evlilik yaşı, tanışma süresi gibi faktörlerin evlilik uyumunu etkilediği görülmüştür (6-8).

Bir annenin bebeğini karnında hissettiği andan itibaren sevgiyle bağlanması yani prenatal bağlanma, çocuğun sağlıklı büyüme ve gelişimini teşvik eden en önemli öğelerden biridir. Çocuğun yaşadığı ilk bağlanma tecrübesi daha sonra yaşayacağı bağlanma tecrübeleri için temel oluşturur $(9,10)$. Eğer anne ile fetüs arasında yaşamın ilk yılında güvenli bağlanmayı başarmada gerekli durumlar karşılanamazsa, bebek emosyonel, sosyal, fiziksel, zihinsel ve dil gelişimi problemleri yaşar. Prenatal bağlanmada başarısızlıkların yaşandığı durumlarda, bebek ihmal ve istismar açısından risk altındadır (11). Prenatal bağlanma, zaman içinde gelişen, özel eşsiz bir ilişkidir. Anne-bebek bağlanma süreci gebelik, doğum ve postpartum periyod süresince gelişir $(12,13)$.

Bu çalışmada, gebelik döneminde çiftler arası uyum ve prenatal bağlanma arasındaki ilişkiyi incelemek amaçlanmıştır. Literatürü incelediğimizde; gebelik döneminde çiftler arası uyum ve prenatal bağlanma arasındaki ilişkinin araştırıldığı kısıtlı sayıda çalışmanın olduğu görülmüş olup çalışmamızın bu konuda literatürü destekleyeceği düşünülmektedir. Ayrıca çalışma sonuçlarımız, gebelik ve doğum sonu döneme hazırlıkta çiftler arası uyumun önemi ile anne bebek bağlanması konularında hemşire ve ebelere yol gösterici olacaktır.

\section{Gereç ve yöntem}

Araştırmanın tipi

Bu araştırma tanımlayıcı ve kesitsel tiptedir.

Araştırmanın yapıldığı yer, zaman ve özellikleri

Bu araştırma, Ocak-Mart 2018 tarihleri arasında bir üniversite hastanesinin kadın hastalıkları-doğum polikliniğine başvuran gebelerde gerçekleştirilmiştir.

\section{Araștırmanın evreni ve örneklemi}

Araştırmanın örneklem sayısı Prenatal Bağlanma Envanteri skoru ile Çiftler Arası Uyum Ölçeği skoru arasında 0,30'luk bir korelasyon öngörülerek, \%5 yanılma payı ve \%99 güç değeriyle $n=195$ gebe olarak hesaplanmıştır. Dahil edilme kriterlerine uyan ve olası kayıplar göz önüne alındığında $n=197$ gebenin çalışmaya alınması gerektiği uygun görülmüştür.

\section{Örneklem seçimi}

Örnekleme seçim kriterleri; 18 yaşından büyük, okur-yazar, iletişim sorunu olmayan (işitme engeli, görme engeli) ve araştırmaya katılmayı kabul eden gebeler çalışma grubunu oluşturmuştur.

\section{Veri toplama araçları}

Veriler araştırmacılar tarafından hazırlanan anket formu, Çift Uyum Ölçeği (ÇUÖ) ve Prenatal Bağlanma Envanteri (PBE) kullanılarak toplanmıştır.

Anket Formu: gebelerin kişisel özelliklerini içeren (yaş, eğitim durumu, çalışma durumu, gelir durumu, yaşadığı yer, eşinin yaşı, eğitim durumu, çalışma durumu, evlilik yaşı, evlilik süresi, evlililik biçimi ve aile tipi) 12 soru, obstetrik özellikleri içeren (gebelik, doğum, abortus, küretaj vajinal doğum sayısı, sezaryen sayısı, gebelik haftası, planlı gebelik durumu, istenen gebelik durumu, gebelik süresince destek olan kişi/kişiler, eşi ile evlilik uyumunu değerlendirme) 7 soru olmak üzere toplam 19 sorudan oluşmaktadır (6-8).

Çift Uyum Ölçeği (ÇUÖ): Spanier tarafından 1976 yılında geliştirilen "Çift Uyum Ölçeği (ÇUÖ)", 2000 yılında Fışıloğlu ve Demir tarafından Türkçe'ye uyarlanmıştır $(14,15)$. Toplam 32 sorudan oluşan ölçek likert tipindedir. Ölçek evliliğin niteliğini, evlilikteki uyumu ve uyumun kalitesini en güvenilir ve geçerli şekilde ölçmekte, aile terapisi alanında, klinik ve araştırma amacıyla evlilik uyumunun ölçümünde yaygın olarak kullanılmaktadır. Ölçek evlilikte eşler arasındaki ilişkinin dört boyutunu ölçmektedir. Bu dört boyut ölçeğin alt boyutlarını oluşturmaktadır. Bunlar: 
1. Eşler arası fikir birliği alt boyutu: Evlilik ilişkisi içinde önemli konularda anlaşma düzeyi, fikir birliği ile ilgili toplam 13 sorudan (1-3, 5, 7-15 numaralı maddeler) oluşmaktadır. Bu bölümden alınabilecek en düşük puan 0, en yüksek puan $65^{\prime}$ tir.

2. Eşler arası tatmin alt boyutu: Duygu ve iletişim ile ilgili olumlu ve olumsuz özellikleri değerlendiren toplam 10 sorudan (16-23, 31, 32 numaralı maddeler) oluşmaktadır. Bu bölümden alınabilecek en düşük puan 0 , en yüksek puan 50 'dir.

3. Duygulanım ifadesi alt boyutu: Sevgi gösterme şekillerinde anlaşma ve sevgi gösterme davranışları ile ilgili toplam 4 sorudan $(4,6,29,30$ numaralı maddeler) oluşmaktadır. Bu bölümden alınabilecek en düşük puan 0 , en yüksek puan 12 'dir.

4. Eşler arası birliktelik alt boyutu: Birlikte geçirilen zamanla ilgili toplam 5 sorudan (24-28 numaralı maddeler) oluşmaktadır. Bu bölümden alınabilecek en düşük puan 0 , en yüksek puan 24'tür (15).

Toplam 32 sorudan oluşan ölçeğin 29. ve 30. sorularının puanları 0-1 puan, 23 . ve 24 . sorularının puanları 0-4 puan, $1-22,25-28$ ve 32 . sorularının puanları 0-5 puan, 31. sorunun puanı ise 0-6 puan arasında değişmektedir. Sher ve Baucom (1993) ölçeğin değerlendirilmesi açısından güvenilir kesme noktasının 101 puan olduğunu bildirmiştir (16). Tüm ölçek için güvenirlik katsayısı 0.96 iken alt bölümler için 0.73 ile 0.94 arasında değişmektedir. Ölçek toplam puan üzerinden değerlendirilmektedir. Ölçekten alınabilecek en düşük puan 0 , en yüksek puan 151 'dir. Toplam puanın yüksek oluşu bireyin ilişkisinin ya da evlilik uyumunun daha iyi olduğunu göstermektedir. Fışıloğlu ve Demir'in geçerlilik güvenilirlik çalışmasında; ÇUÖ'nün Türkçe versiyonunun Cronbach Alfa katsayısı 0.92 olarak bulunmuştur (15). Bu çalışmada Çift Uyum Ölçeğinin Cronbach alfa katsayısı 0.95 olarak bulunmuştur.

Prenatal Bağlanma Envanteri (PBE) - Prenatal Attachment Inventory: Mary Muller tarafından gebelik boyunca kadınların yaşadıkları düşünceleri, duyguları, durumları açıklamak ve bebeğe prenatal dönemdeki bağlanma düzeylerini belirlemek amacıyla 1990 yılında geliştirilmiş 21 maddelik bir ölçektir (17). Türkçeye uyarlanması Yılmaz ve Beji tarafından 2013 yılında yapılmıştır (18). Her madde 1 ile 4 arasında puan alabilen dörtlü likert tiptedir. Ölçekten en az 21 en fazla 84 puan alınabilmektedir.
Gebenin aldığı puanın artması bağlanma düzeyinin de artıı̆ını göstermektedir (18). Bu çalışmada Prenatal Bağlanma Envanterinin Cronbach alfa katsayısı 0.99 olarak bulunmuştur.

\section{Verilerin toplanması}

Veriler araştırmacılar tarafından bir üniversite hastanesinin kadın hastalıkları ve doğum polikliniğinde özel bir görüşme odasında, yüz yüze görüşme yöntemi ile ortalama $10 \mathrm{dk}$ sürede toplanmıştır.

\section{Araştırmanın etiği}

Araştırmanın etik açıdan uygunluğu için Üniversitenin Tıp Fakültesi Dekanlığı Bilimsel Araştırmalar Etik Kurulu'ndan 2018/34 sayılı etik onay alındıktan sonra Başhekimlik'ten kurum izni alınarak araştırmaya başlanmıştır. Çalışmaya katılmayı kabul eden gönüllü gebelerden bilgilendirilmiş sözlü onam alınmıştır.

\section{Istatistiksel analiz}

Çalışmada elde edilen bulgular değerlendirilirken, istatistiksel analizler için SPSS (Statistical Package for Social Sciences) for Windows 23,0 (IBM Statistical Package for the Social Sciences, version 23.0 IBM Corp.; Armonk, NY, $A B D)$ programı kullanılmıştır. Gebelerin kişisel ve obstetrik özellikleri tanımlayıcı istatistikler kullanarak (ortalama, standart sapma, yüzde) değerlendirilmiştir. Ölçek skorlarının dağııım özellikleri incelenerek; 2 kategoriden oluşan değişkenler için Mann Whitney $U$ testi, 3 ya da daha fazla kategoriden oluşan değişkenler için Kruskal Wallis testleri kullanılmıştır. Analizler öncesinde Kolmogorov-Smirnov testi ile normallik dağılımına bakılmıştır ve değişkenlerin normal dağılım göstermediği bulunmuştur. Değişkenler arası ilişkileri incelemede Pearson korelasyon analizi kullanılmıştır. $p<0.05$ değeri istatistiksel anlamlılık sınır değeri olarak kabul edilmiştir.

\section{Bulgular}

Gebelerin yaş ortalaması $29,5 \pm 6,3$, eşlerin yaş ortalaması $32,2 \pm 7,2$, evlilik yaşı ortalaması $22,5 \pm 3,6$, evlilik süre ortalaması 7,1 $1 \pm 6,4$ olarak bulunmuştur. Gebelerin \%66.0'ının ( $n=130)$ eğitim durumu lise ve üstü olduğu, \%56.3'ünün ( $n=111)$ çalıştığı, \%77.2'sinin $(n=152)$ gelirinin gidere eşit olduğu, \%55.8'inin ( $n=110)$ ilde yaşadığı, \%70.6'sının $(n=139)$ eşinin eğitim durumunun lise ve üstü olduğu, \%93.9'unun ( $n=185$ ) eşinin çalıştığı, \%82.7'sinin $(n=163)$ aile tipinin çekirdek aile olduğu ve \%71.1'inin ( $n=140$ ) evlilik biçiminin tanışarak olduğu bulunmuştur. Çalışmaya katılan gebelerin kişisel özellikleri Tablo 1'de gösterilmiştir. 
Gebelerin gebelik ortalaması $2,1 \pm 1,4$, doğum ortalaması $1,6 \pm 0,9$, abortus ortalaması $1,3 \pm 0,7$, küretaj ortalaması $1,3 \pm 0,8$, vajinal doğum sayısı $1,5 \pm 0,9$, sezaryen doğum sayısı $1,3 \pm 0,5$, gebelik haftası ortalaması $25,6 \pm 8,7$ bulunmuştur. Gebelerin \%49.2'sinin ( $n=97)$ 3. trimester, \%71.6'sının ( $n=141)$ planlı gebelik, \%82.2'sinin $(n=162)$

Tablo 1. Gebelerin sosyodemografik özellikleri $(n=197)$

\section{$\bar{X} \pm S S$}

\begin{tabular}{lc}
\hline Yaş & $29,5 \pm 6,3(\min : 18-\max : 45)$ \\
Eşin Yaşı & $32,2 \pm 7,2(\min : 18-\max : 51)$ \\
Evlilik Yaşı & $22,5 \pm 3,6(\min : 15-\max : 40)$ \\
Evlilik Süresi & $7,1 \pm 6,4(\min : 1-\max : 27)$ \\
\hline & $\boldsymbol{n}$
\end{tabular}

\section{Eğitim durumu}

İlköğretim ve altı

67

34,0

Lise ve üstü

130

66,0

Çalışma Durumu

\begin{tabular}{lcc} 
Çalışıyor & 86 & 43,7 \\
Çalışmıyor & 111 & 56,3 \\
\hline
\end{tabular}

\section{Gelir Durumu}

\begin{tabular}{lcc} 
Gelir giderden az & 31 & 15,7 \\
Gelir gidere eşit & 152 & 77,2 \\
Gelir giderden fazla & 14 & 7,1 \\
\hline Yaşanılan Yer & 22 & 11,2 \\
Köy & 65 & 33,0 \\
İlçe & 110 & 55,8 \\
İ & & \\
\hline Eşin Eğitim Durumu & 58 & 29,4 \\
İlköğretim ve altı & 139 & 70,6 \\
Lise ve üstü & & \\
\hline Eşin Çalışma Durumu & 185 & 93,9 \\
Çalışıyor & 7 & 3,6 \\
Çalışmıyor & 3 & 1,5 \\
Emekli & 2 & 1,0 \\
Diğer & & \\
\hline Evlenme Biçimi & 140 & 71,1 \\
Tanışarak & 55 & 27,9 \\
Görücü Usulü & 2 & 1,0 \\
Diğer & & \\
\hline Aile Tipi & & \\
Çekirdek Aile & & \\
Geniş Aile & & \\
\hline X̌: & & \\
\hline & & \\
\hline
\end{tabular}

$\overline{\mathbf{X}}$ : ortalama; SS: standart sapma, min: minumum, max: maksimum istenen gebelik olduğu, \%83.8'inin ( $n=164)$ gebelikte duygusal destek aldığı, \%77.7'sinin ( $n=153)$ eşinden ve $\% 74.1$ 'inin ailesinden duygusal destek aldığı ve \%47.7'sinin $(n=94)$ evlilik uyumunun çok iyi olduğunu düşündüğü bulunmuştur. Çalışmaya katılan gebelerin obstetrik özellikleri Tablo 2'de gösterilmiştir.

Tablo 2. Gebelerin obstetrik özellikleri $(n=197)$

\begin{tabular}{|c|c|c|}
\hline & \multicolumn{2}{|c|}{$\bar{X} \pm S S$} \\
\hline Gebelik & \multicolumn{2}{|c|}{$2,1 \pm 1,4(\min : 1-\max : 10)$} \\
\hline Doğum & \multicolumn{2}{|c|}{$1,6 \pm 0,9(\min : 1-\max : 5)$} \\
\hline Abortus & \multicolumn{2}{|c|}{$1,3 \pm 0,7(\min : 1-\max : 4)$} \\
\hline Küretaj & \multicolumn{2}{|c|}{$1,3 \pm 0,8(\min : 1-\max : 3)$} \\
\hline Vajinal doğum sayısı & \multicolumn{2}{|c|}{$1,5 \pm 0,9(\min : 1-\max : 5)$} \\
\hline Sezaryen doğum sayısı & \multicolumn{2}{|c|}{$1,3 \pm 0,5(\min : 1-\max : 3)$} \\
\hline \multirow[t]{2}{*}{ Gebelik Haftası } & \multicolumn{2}{|c|}{$25,6 \pm 8,7$ (min:4 - max:40) } \\
\hline & $n$ & $\%$ \\
\hline \multicolumn{3}{|l|}{ Trimester } \\
\hline 1 & 16 & 8,1 \\
\hline 2 & 84 & 42,6 \\
\hline 3 & 97 & 49,2 \\
\hline \multicolumn{3}{|l|}{ Planlı Gebelik } \\
\hline Hayır & 56 & 28,4 \\
\hline Evet & 141 & 71,6 \\
\hline
\end{tabular}

\begin{tabular}{lcc}
\hline Istenen Gebelik & & \\
Hayır & 35 & 17,8 \\
Evet & 162 & 82,2 \\
\hline Gebelikte duygusal destek var mI? & & \\
Hayır & 33 & 16,2 \\
Evet & 164 & 83,8 \\
\hline
\end{tabular}

Duygusal destek sağlayanlar*

\begin{tabular}{lcc} 
Aile & 146 & 74,1 \\
Eş & 153 & 77,7 \\
Arkadaş & 100 & 50,8 \\
Akraba & 25 & 12,7 \\
Diğer & 1 & 0,5 \\
\hline
\end{tabular}

\section{Evlilik uyumu}

Çok kötü $\quad 9 \quad 4,6$

Kötü $20 \quad 10,2$

Orta $12 \quad 6,1$

$\begin{array}{lll}\text { İyi } & 62 & 34,5\end{array}$

Çok iyi $94 \quad 47,7$

$\overline{\boldsymbol{X}}$ : ortalama; $\mathbf{S S}$ : standart sapma, min: minumum, max: maksimum *Birden fazla işaretleme yapıımıştır. 
Gebelerin Prenatal Bağlanma Envanteri (PBE)'i puan ortalaması $64,89 \pm 21,15$ olarak bulunmuştur. Çift Uyum Ölçeği (ÇUÖ) puan ortalamasının 91,73 $\pm 32,33$, eşler arası fikir birliği alt boyut puan ortalaması 91,73 $\pm 32,33$, eşler arası tatmin alt boyut puan ortalamasının $44,25 \pm 20,28$, duygulanım ifadesi alt boyut puan ortalamasının $8,43 \pm 3,85$, eşler arası birliktelik alt boyut puan ortalamasının 15,33 $\pm 7,24$ olduğu bulunmuştur. Çalışmaya katılan gebelerin PBE toplam puan ortalaması ile ÇUÖ toplam ve alt boyut puan ortalamaları Tablo 3'te gösterilmiştir.

Tablo 3. Gebelerin PBE toplam puan ortalaması ile ÇUÖ toplam ve alt boyut puan ortalamaları $(n=197)$

\begin{tabular}{|c|c|c|c|}
\hline & Minimum & Maksimum & $\bar{X} \pm S S$ \\
\hline PBE toplam puanı & 21 & 84 & $64,89 \pm 21,15$ \\
\hline \multicolumn{4}{|l|}{$\begin{array}{l}\text { ÇUÖ toplam ve alt boyut } \\
\text { puanları }\end{array}$} \\
\hline Toplam ÇUÖ & 5 & 130 & $91,73 \pm 32,33$ \\
\hline Eşler Arası Fikir Birliği & 0 & 65 & $44,25 \pm 20,28$ \\
\hline Eşler Arası Tatmin & 5 & 32 & $23,69 \pm 3,50$ \\
\hline Duygulanım İfadesi & 0 & 12 & $8,43 \pm 3,85$ \\
\hline Eşler Arası Birliktelik & 0 & 24 & $15,33 \pm 7,24$ \\
\hline
\end{tabular}

Çalışmada gebelerin ÇUÖ ve PBE puanları arasında pozitif yönde anlamlı ilişki saptanmıştır $(r=0,80 ; p<0,001)$. Gebelerin ÇUÖ ve PBE puanları arasındaki ilişki Tablo 4'te gösterilmiştir.

Tablo 4. Gebelerin ÇUÖ ve PBE toplam puan ortalamaları arasındaki ilişki $(n=197)$

\begin{tabular}{lccc} 
& $\boldsymbol{n}$ & $\boldsymbol{r}$ & $\boldsymbol{p}$ \\
\hline ÇUÖ & 197 & $0,80 *$ & $<0,001$ \\
PBE & 197 & & \\
\hline *Pearson Correlations & & &
\end{tabular}

Çalışmada eğitim durumu lise ve üzeri olan, çalışan, gelir durumu gidere eşit olan, tanışarak evlenen, planlı gebelik yaşayan ve gebelik süresince duygusal ya da fiziksel olarak destek alan gebelerin ÇUÖ ve PBE puan ortalamalarının anlamlı olarak yüksek olduğu belirlenmiştir $(p<0,001)$. Ayrıca 3. trimester gebelerin PBE puan ortalamalarının 1. ve 2. Trimester gebelere göre anlamlı olarak daha yüksek olduğu saptanmıştır $(p<0,001)$.

Çalışmaya katılan gebelerin kişisel özellikleri ile ÇUÖ ve PBE puan ortalamalarının karşılaştırılması Tablo 5'te gösterilmiştir.

Tablo 5. Gebelerin kişisel özellikleri ile ÇUÖ ve PBE toplam puan ortalamalarının karşış̧̧ııııması $(n=197)$

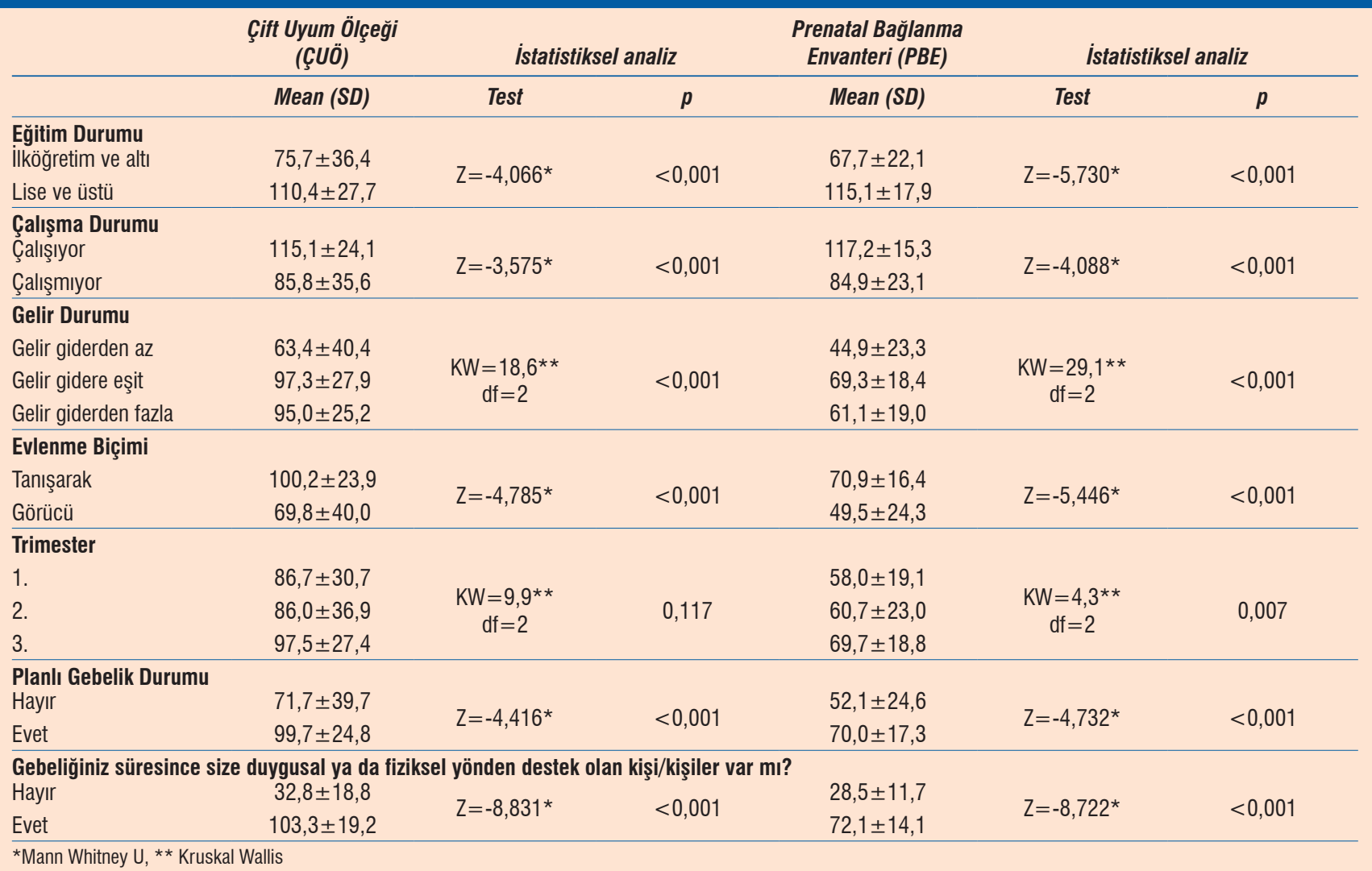




\section{Tartışma}

Gebelik sürecinde kadınlar anatomik, fizyolojik ve psikolojik birçok değişiklikle başa çıkmaya çalışmaktadırlar. Eş desteği ile beraber sağlıklı geçirilen gebelik süreci hem doğum öncesi bebeğe bağlanmayı hem de çift uyumunu olumlu yönde etkilemektedir. Doğum öncesi bağlanma, ebeveynler ve doğmamış çocukları arasında gelişen duygusal bir bağdır. Gebelik döneminde gerçekleşen bağlanma, doğum sonrası anne ve bebek arasındaki ilişkinin temelini oluşturmaktadır.

Çalışmada gebelerin prenatal bağlanmalarının $(64,89 \pm 21,15)$ iyi düzeyde olduğu bulunmuştur (Tablo 3). Küçükkelepçi ve ark. (19) gebelikte beden imajı algısı ve prenatal bağlanmayı etkileyen faktörleri inceledikleri çalışmalarında, gebelerin prenatal bağlanmalarının $(43,84 \pm 9,71)$ orta düzeyde olduğunu belirlemişlerdir. Dağlı (20) gebelikte bebeğe yönelik yapılan hazırlıkların prenatal bağlanma ile ilişkisini incelediği çalışmasında, gebelerin prenatal bağlanmalarının $(61,10 \pm 10,95)$ iyi düzeyde olduğunu bulmuştur. Çınar ve ark. (21) gebe kadınlarda sağlıklı yaşam uygulamaları ile prenatal bağlanma ve yorgunluk arasındaki ilişkiyi inceledikleri çalışmalarında, düzenli prenatal takibe gelen gebelerin prenatal bağlanmalarının (55 [45-64]) iyi düzeyde ve düzenli prenatal takibe gelmeyen gebelerin prenatal bağlanmalarının (42 [30-52]) orta düzeyde olduğunu saptamışlardır. Aksoy ve ark. (22) riskli gebeliklerde prenatal bağlanma ve sosyal desteği inceledikleri çalışmalarında, gebelerin prenatal bağlanmalarının $(56,76 \pm 9,23)$ iyi düzeyde olduğunu belirlemişlerdir. Buko ve Özkan (23) gebelerin duygusal zekaları ile prenatal bağlanma düzeyleri arasındaki ilişkiyi inceledikleri çalışmada, gebelerin prenatal bağlanmalarının $(65,12 \pm 11,12)$ iyi düzeyde olduğu bulunmuştur. Elkin (24) gebelerin prenatal bağlanma düzeyleri ve etkileyen faktörleri incelediği çalışmasında, prenatal bağlanmanın $(57,32 \pm 12,32)$ iyi düzeyde olduğunu saptamıştır. Tani ve ark. (25) yaptıkları çalışmada, gebelerin prenatal bağlanmalarının $(60,62 \pm 10,49)$ iyi düzeyde olduğunu bildirmiştir. Harpel ve ark. (26) prenatal bağlanma üzerine ultrasonun etkisini inceledikleri çalışmada, prenatal bağlanmanın $(42,11)$ orta düzeyde olduğunu belirlemişlerdir. Busonera ve ark. (27) İtalyan gebe kadınlar üzerinde yürüttükleri çaIışmada, prenatal bağlanmanın $(63,11 \pm 8,89)$ iyi düzeyde olduğunu bildirmişlerdir. Çalışma bulgumuz ve literatür bulguları gebelerin prenatal bağlanmalarının genellikle iyi düzeyde olduğunu göstermektedir. Ancak gebelikte yaşanan değişiklilere uyum ve diğer faktörlerin etkilerinin doğum öncesi anne bebek bağlanması düzeyinde değişkenlik gösterebileceği söylenebilir.
Çalışmada gebelerin eşleri ile olan çift uyumlarının $(91,73 \pm 32,33)$ oldukça iyi düzeyde olduğu saptanmıştır (Tablo 3). Molgora ve ark. (28) gebelik sırasında evlilikle başa çıkma ve çift uyumunu inceledikleri çalışmalarında, gebelerin eşleri ile olan çift uyumlarının $(125,27 \pm 13,17)$ oldukça iyi düzeyde olduğunu saptanmışlardır. Rollé ve ark. (29), gebelerin eşleri ile olan çift uyumlarının $(110,0 \pm 11,8)$ oldukça iyi düzeyde olduğunu bildirmişlerdir. Güneş ve ark. yaptıkları çalışmada (30), gebelerin eşleri ile olan çift uyumlarının $(104,9 \pm 14,9)$ oldukça iyi düzeyde olduğunu saptamıştır. Akkaş (31) gebelik döneminde eşler arası uyumu incelediği çalışmada, gebelerin eşleri ile olan çift uyumlarının $(96,35 \pm 2,16)$ iyi düzeyde olduğunu saptanmışlardır. Literatür ve çalışma bulgumuz gösteriyor ki; gebelik sürecinde birer anne ve baba adayı olan çiftler arasındaki etkileşim artarak çift uyumu üzerinde olumlu bir etki yaratmaktadır.

Çalışmada gebelerin eşleri ile aralarındaki fikir birliğinin, sevgilerini gösterme davranış biçimlerinin, birlikte geçirilen zamanın iyi, duygu ve iletişimden tatminin ise orta düzeyde olduğu belirlenmiştir (Tablo 3). Rollé ve ark. çaIışmasında (29), gebelerin eşleri ile aralarındaki fikir birliğinin, sevgilerini gösterme davranış biçimlerinin, birlikte geçirilen zamanın ve duygu tatmininin iyi, iletişimden tatminin ise orta düzeyde olduğu belirlenmiştir. Güneş ve ark. (30) yaptıkları çalışmada, gebelerin eşleri ile aralarındaki fikir birliğinin, sevgilerini gösterme davranış biçimlerinin, birlikte geçirilen zamanın iyi, duygu ve iletişimden tatminin ise orta düzeyde olduğu saptanmıştır. Akkaş (31) yaptığı çalışmada, gebelerin eşleri ile aralarındaki fikir birliğinin, iletişimden tatminin ve duygu tatmininin iyi, sevgilerini gösterme davranış biçimlerinin, birlikte geçirilen zamanın ise orta düzeyde olduğu bulunmuştur. Gebelik sürecinde eşler arası uyumun göstergeleri olan "fikir birliği, sevgilerini gösterme davranış biçimleri, birlikte geçirilen zaman, duygu ve iletişimden tatmin"in iyi ya da orta düzeyde olması, uyumlu bir ilişki yaşandığını göstermektedir. Literatür ve çalışmamız bulguları benzerdir. Gebelik süreci, anne adayı için psikolojik açısından hassas bir süreç olması nedeniyle, baba adaylarının gebe ile daha fazla etkileşime geçmesinin önemli olduğu düşünülmektedir.

Gebelik sürecinde eş ile sağlanan uyum, anne adayını psikolojik olarak rahatlatarak annelik rolünü daha etkin şekilde kabullenmesini sağlamakta ve prenatal bağlanmayı artırmaktadır. Bu doğrultuda çalışmada, gebelerin çift uyum düzeyleri arttıkça prenatal bağlanma düzeylerinin de arttığı tespit edilmiştir (Tablo 4). Ülkemizde Nacar ve ark. (32) yaptığı çalışmada, çift uyum düzeyi artışı ile prenatal bağlanma düzeyi artışı arasında zayıf bir ilişki 
olduğunu bildirilmiştir. Ancak çalışmamıza benzer olarak Cox ve ark. (33) evlilik yaşamında ebeveyn ve bebek bağlanmasını inceledikleri çalışmada; evlilik sürecinde anneler doğmamış bebeklerine karşı daha fazla olumlu tutum içinde olduklarında, bebekleri ve eşlerine karşı daha sıcak ve duyarlı davranarak ebeveyn rolünü kazandıkları ve evliliğin önemli bir rol oynadığı bildirmişlerdir. Mazzeschi ve ark. (34) primiparlarda stres hikayesi; bağlanma tarzı, prenatal bağlanma ve çift uyumunun incelendiği çalışmada, çift uyum düzeyi artışı ile prenatal bağlanma düzeyi artışı arasında kuvvetli bir ilişki olduğu belirlenmiştir. Evlilik yaşamında çift uyumunun olması ve devamında bebek sahibi olmaya karar verme süreci çiftler arasındaki bağı daha da güçlendirmekte ve annelik rolünün kazanılmasında önemli olmaktadır. Çalışmamız ve literatür doğrultusunda söylenebilir ki; evlilikte çift uyumu, doğum öncesi anne adayının bebeğine bağlama duygusunu artırmaktadır.

Çalışmada lise ve üstü gebelerin, ilköğretim ve altına göre eğitim durumu arttıkça prenatal bağlanmanın ve çift uyumunun anlamlı olarak arttığı tespit edilmiştir (Tablo 5). Benzer şekilde Dağlı (20), Çınar ve ark. (21), Akkaş (31), Nacar ve ark. (32) ve Tunçel ve Süt (35) yaptıkları çalışmada, gebelerin eğitim durumu yükseldikçe prenatal bağlanmaIarının daha yüksek olduğunu belirlemiştir. Küçükkelepçi ve ark. (19) yaptıkları çalışmada, ilköğretim mezunu gebelerin diğer gebelere göre prenatal bağlanmalarının daha yüksek olduğu bulunmuştur. Durualp ve ark. (36) evlilik doyumu ve maternal bağlanma arasındaki ilişkiyi inceledikleri çalışmalarında, annelerin eğitim durumu arttıkça (üniversite mezunlarının diğer mezunlara göre) çift uyumunun daha yüksek olduğunu saptanmıştır. Kadınların tüm yaşam dönemlerinde önemli olduğu gibi gebelik ve doğum süreçlerinin yaşandığı üreme çağı döneminde eğitim seviyelerinin yüksek olması önemlidir. Gebe kadınların lise ve üstü eğitim seviyesine sahip olmasının eşleri ile çift uyumunu ve bebeği ile arasındaki doğum öncesi bağlanmayı olumlu yönde etkileyeceği söylenebilir.

Araştırmada, çalışan gebelerin prenatal bağlanma ve çift uyum düzeylerinin çalışmayanlara göre anlamlı olarak daha fazla arttığı bulunmuştur (Tablo 5). Dağlı (20), Çınar ve ark. (21) ve Elkin (24) yaptıkları çalışmalarında, çalışan gebelerin çalışmayan gebelere göre prenatal bağlanmalarının daha yüksek olduğunu saptamıştır. Durualp ve ark. (36) yaptığı çalışmada, çalışan annelerin diğerlerine göre çift uyumunun daha yüksek olduğunu saptanmıştır. Çalışma bulgumuz literatüre benzerlik göstermektedir. Çalışan gebelerin, maddi yönden eve katkıda bulunmalarının ve gebelik sürecinde de çalışma yaşamına dahil olmalarının vermiş olduğu doyumun prenatal bağlanma veçift uyumunu olumlu yönde etkilediği düşünülmektedir.

Çalışmada gelir durumu, gelir gidere eşit olan gebelerin, prenatal bağlanma ve çift uyum düzeylerinin geliri giderden az olan ve geliri giderden fazla olanlara göre anlamlı olarak daha fazla olduğu saptanmıştır (Tablo 5). Dağıı (20) yaptığı çalışmada, gelir durumu iyi olan gebelerin, gelir durumu orta ve kötü olan gebelere göre prenatal bağlanmalarının daha yüksek olduğunu tespit etmiştir. Çınar ve ark (21) yaptıkları çalışmada, gebelerin gelir düzeyi arttıkça (gelir giderden az olanlara göre gelir gidere eşit olanların, gelir giderden az olanlara göre gelir gidere fazla olanların) prenatal bağlanmalarının daha yüksek olduğunu saptanmıştır. Elkin (24) yaptığı çalışmada, geliri giderden fazla olan gebelerin diğerlerine göre prenatal bağlanmalarının daha yüksek olduğu bulunmuştur. Durualp ve ark. (36) yaptığı çalışmada, geliri giderden fazla olan annelerin diğerlerine göre çift uyumunun daha yüksek olduğunu saptanmıştır. Gelir durumun iyi olması evlilik yaşantısının gerektirdiği intiyaçları karşılamak açısından önemlidir. Gebelik ve doğum sürecinde giderler içerisine bebeğin de masrafları ekleneceğinden dolayı hane içerisine giren gelirin iyi ya da orta düzeyde olmasının çift uyumunu ve bebeğe bağlanmayı artırdığı düşünülmektedir.

Çalışmada tanışarak evlenen gebelerin, görücü usulü ile evlenenlere göre prenatal bağlanma ve çift uyum düzeylerinin anlamlı olarak daha fazla arttığı tespit edilmiştir (Tablo 5). Durualp ve ark'nın (36) yaptığı çalışmada, arkadaş olarak evlenen annelerin diğerlerine göre çift uyumunun daha yüksek olduğunu saptanmıştır. Akkaş (31) yaptığı çalışmada, anlaşarak/isteyerek evlenen gebelerin diğerlerine göre çift uyumunun daha yüksek olduğunu belirlenmiştir. Evlilik öncesi çiftlerin birlikte geçirdikleri zaman birbirlerini tanımaları ve birbirlerine uygun olup olmadıklarını düşünmeleri için uygun bir zaman dilimidir. Tanışarak ve birbirlerini sevgi saygı göstererek evlenen çiftlerin gebelik sürecinde de çift uyumları ve dolayısıyla annenin bebeğe bağlanması daha güçlü olacaktır.

Çalışmada gebelik trimesterleri ilerledikçe (1. trimestere göre 3. trimesterde, 2 . trimestere göre 3 . trimesterde) prenatal bağlanmanın ve çift uyum düzeylerinin anlamlı olarak daha fazla arttığı saptanmıştır (Tablo 5). Busonera ve ark.'nın (27) yaptıkları çalışmada, 3. trimesterde olan gebelerin 2. trimesterde olan gebelere göre daha yüksek prenatal bağlanmaları olduğu bulunmuştur. Tunçel ve Süt (35) yaptıkları çalışmada, gebelik trimesteri arttıkça prenatal bağlanmanın arttığı, 1. trimestere göre 2. trimester, 2 . 
trimestere göre 3. trimester, 1 . trimestere göre 3. trimester gebelerinde daha yüksek prenatal bağlanma olduğu belirlenmiştir. Güney ve Uçar (37) 3. trimester gebelerde maternal-fetal bağlanma üzerine fetal hareketlerin etkisini inceledikleri çalışmada, fetüs hareketlerini takip eden gebelerin bebeğe bağlanma düzeylerinin daha fazla olduğu tespit edilmiştir. Malm ve ark. (38) gebelerde fetal hareket ile prenatal bağlanmayı inceledikleri çalışmada, 3. trimester gebelerde hissedilen fetal hareket sıklığı ve şiddeti arttıkça prenatal bağlanmanın da arttığı belirlenmiştir. Gebelik sürecinde trimesterlar ilerledikçe ve anne adayı bebeğin hareketlerini daha yoğun hissetmeye başladıkça doğum öncesi bağlanmanın artması gebeliklerde beklenen bir sonuçtur. Baba adayı da anne karnında büyüyen bebekle ve anne adayı ile daha fazla yakınlaşarak çift uyumunda artış olmaktadır.

Çalışmada planlı gebelik yaşayanların, plansız gebelik yaşayanlara göre prenatal bağlanma ve çift uyum düzeylerinin anlamlı olarak daha fazla arttığı saptanmıştır (Tablo 5). Nacar ve ark. (32) yaptıkları çalışmada, gebeliği planlı olan gebelerin diğer gebelere göre prenatal bağlanmalarının daha yüksek olduğu saptanmıştır. Elkin (24) yaptığı çalışmada, gebeliği planlı olan gebelerin diğer gebelere göre prenatal bağlanmalarının daha yüksek olduğu bulunmuştur. Durualp ve ark. (36) yaptığı çalışmada, planlı bir gebelik geçiren annelerin diğerlerine göre çift uyumunun daha yüksek olduğunu saptanmıştır. Akkaş (31) yaptığı çalışmada, planlı bir gebelik geçiren gebelerin diğerlerine göre çift uyumunun daha yüksek olduğu belirlenmiştir. Çalışma sonucunda elde edilen bulgular literatüre benzerlik göstermektedir. Çiftlerin bebek sahibi olmadan önce gebelik, doğum ve doğum sonrası sürece hazırlanmaları, planlı bir şeklide istenilen zaman ve sayıda çocuğa sahip olmalarını sağlayacaktır. Planlı olarak gerçekleşen gebeliklerde, hem gebe hem de eşi bu sürece hazır olup doğum öncesi bebeğe bağlanma ve çift uyumu da artacaktır.

Çalışmada gebeliği süresince duygusal ya da fiziksel yönden destek alan gebelerin, destek almayan gebelere göre prenatal bağlanma ve çift uyum düzeylerinin anlamlı

\section{Kaynaklar}

1. Mazzeschi C, Pazzagli C, Radi G, Raspa V, Buratta L. Antecedents of maternal parenting stress: the role of attachment style, prenatal attachment, and dyadic adjustment in first-time mothers. Frontiers in Psychology 2015; 6: 1443. [CrossRef]

2. Taşkın L. Doğum ve Kadın Sağlığı Hemşireliği, 11.Baskı, Ankara: Akademisyen Tıp Kitabevi; 2016. p.462-90.

3. Çetin FC, Tan A, Merih YD. Türk müziğinin gebelik ve yenidoğan üzerindeki etkileri. Zeynep Kamil Tıp Bülteni 2017; 48: 124-30. [CrossRef] olarak daha fazla arttığı saptanmıştır (Tablo 5). Ossa ve ark. (39) gebelikte alınan aile desteğinin doğum öncesi bağlanmayı arttırdığını belirlemiştir. Metin (40) en yüksek sosyal desteğin eş ve aileden alındığını; Hergüner ve ark. (41) ve Aksoy ve ark. (42) algılanan sosyal destek ile doğum öncesi bağlanma arasında pozitif yönde bir ilişki olduğunu bildirmişlerdir. Tunçel ve Süt (35) yaptıkları çalışmada, yakın desteği arttıkça gebelerde daha yüksek prenatal bağlanma olduğu bulunmuştur. Akkaş (31) yaptığı çalışmada, duygusal ya da fiziksel yönden sosyal destek alan, eş desteği alan ve eş desteği algısı çok iyi olan gebelerin, destek almayan gebelere göre çift uyumlarının daha yüksek olduğunu belirlenmiştir. Yekenkunrul (43) gebelikte bulantı kusma, evlilik uyumu ve eşilişkisi arasındaki ilişkiyi incelediği çalışmada, eşten algılanan eş ilişkisi düzeyi arttıkça, evlilik ve çift uyumunun arttığı saptanmıştır. Literatür ve çalışmamızın benzer sonuçlara ulaştığı görülmektedir. Buna göre, gebelik sürecinde eş ve yakınların duygusal ve fiziksel yönden anne adayına destek olmaları, gebeyi fiziksel ve duygusal açıdan destekleyerek bebeğe bağlanmasını arttırmakta ve çift uyumunu olumlu yönde etkilemektedir.

\section{Sonuç ve öneriler}

Çalışma sonuçlarımız gösteriyor ki; gebelerin prenatal bağlanma ve çift uyumu iyi düzeydedir. Gebelerin çift uyumu arttıkça prenatal bağlanma düzeyleri de artmaktadır. Ayrıca lise ve üstü eğitim, çalışan, geliri giderine eşit olan, tanışarak evlenen, gebelik trimester artışı, planlı gebelik yaşayan, duygusal ya da fiziksel yönden destek alan gebelerin çift uyumu ve prenatal bağlanması daha yüksektir.

Sonuçlar doğrultusunda; kadın sağlığı alanında çalışan hemşirelerin ve sağlık profesyonellerinin, gebelerin hikayeleri hakkında bilgi alırken prenatal bağlanma ve çift uyumlarını değerlendirmeleri, değerlendirmeler sonucunda gebeye uygun hemşirelik girişimleri planlayarak eğitim vermeleri ve prenatal bağlanma ile çift uyumunun gebelik üzerine etkisi hakkında ileri düzeyde araştırmalar yapılması önerilebilir.

4. Kumcağız $H$, Güner,Z. Hemşirelerin iş doyumlarının yordayıcısı olarak sosyal destek, evlilik uyumu ve bazı değişkenler açısından incelenmesi. Journal of Human Sciences. 2017; 14: 225-49. [CrossRef]

5. Şen E, Bulut S, Şirin A. Primer infertil kadınlarda eşlerarası uyumun incelenmesi. Florence Nightingale Hemşirelik Dergisi 2014;22: 17-24.

6. Yanikkerem E, Goker A, Ustgorul S, Karakus A. Evaluation of sexual functions and marital adjustment of pregnant women in Turkey. International Journal of Impotence Research 2016; 28: 176-83. [CrossRef] 
7. Li A, Robustelli BL, Whisman MA. Marital Adjustment and Psychological Distress in Japan. Journal of Social and Personal Relationships 2016; 33: 855-66.

8. Haylı RG, Durmuş E, Kış A. Evlilik doyumunun cinsiyet açısından incelenmesi: Bir meta-analiz çalışması. Journal of Human Sciences 2017; 14: 3328-42.

9. Sabuncuoğlu $\mathrm{O}$, Berkem $\mathrm{M}$. Bağlanma biçemi ve doğum sonrası depresyon belirtileri arasındaki ilişki: Türkiye'den bulgular. Türk Psikiyatri Dergisi 2006; 17: 252-8.

10. Mutlu C, Yorbik Ö, Tanju IA, Çelikel F, Sezer RG. Doğum öncesi, doğum sırası ve doğum sonrası etkenlerin annenin bağlanması ile ilişkisi. Anadolu Psikiyatri Dergisi 2015; 16:442-50. [CrossRef]

11. Altıntaş $M$, Kesebir S, İnanç L. Güneydoğu'da bir ilçe devlet hastanesine başvuran erken ve erişkin yaştaki gebeliklerin anksiyete, depresyon ve bağlanma açısından karşılaştırılması. Yeni Symposium Dergisi 2016; 54: 19-24. [CrossRef]

12. Uytun $M C ̧$, Öztop DB, Eşel E. Ergenlikte ve erişkinlikte bağlanma davranışının değerlendirilmesi. Düşünen Adam: Psikiyatri ve Nörolojik Bilimler Dergisi 2013; 26: 177-89.

13. Morsünbül Ü, Çok F. Bağlanma ve İlişkili Değişkenler. Psikiyatride Güncel Yaklaşımlar 2011; 3: 553-70.

14. Spanier GB. Measuring Diyadic Adjusment: A new scale for assesting the quality of marriage and the similar dyads, J Marriage Fam 1976; 38: 15-28. [CrossRef]

15. Fışıloğlu H, Demir A. Applicability of the dyadic adjustment of marital quality with Turkish couples. European Journal of Psychological Assessment 2000; 16: 214-8. [CrossRef]

16. Sher TG, Baucom DH. Marital communication: differences among martially distressed, depressed, and non-distressed non-depressed couples. Journal of Family Psychology 1993; 1: 148-53. [CrossRef]

17. Muller ME, Ferketich S. Factor analysis of the maternal fetal attachment scale. Nursing Research 1993;42:144-47.

18. Yılmaz SD, Beji NK. Turkish version of prenatal attachment inventory: a study of reliability and validity. Anadolu Hemşirelik ve Sağlık Bilimleri Dergisi 2013; 16: 103-09.

19. Küçükkelepçe DŞ, Özkan SA, Özkan TK. Gebelikte beden imajı algısı ve prenatal bağlanmayı etkileyen faktörler. I. Uluslararası ve II. Ulusal Kadın Sağılığı Hemşireliği Kongresi, 23-24 Mart 2018, İstanbul. (Poster Sunum PP-020).

20. Dağlı K. Gebelikte bebeğe yönelik yapılan hazırlıkların prenatal bağlanma ile ilişkisi. Adnan Menderes Üniversitesi Fen Bilimleri Enstitüsü Yüksek Lisans Tezi. 2017. Aydın.

21. Cınar N, Caka SY, Topal S, Yuvacı HU, Erkorkmaz U. The Relation of Health-Related Practices of Pregnant Women, Fatigue and Prenatal Attachment. Journal of the College of Physicians and Surgeons-Pakistan: JCPSP 2017; 27: 693-8.

22. Aksoy YE, Yılmaz SD, Aslantekin F. Riskli Gebeliklerde Prenatal Bağlanma ve Sosyal Destek. Turkiye Klinikleri Journal of Health Sciences 2016; 1: 163-9. [CrossRef]

23. Buko G, Özkan H. Gebelerin duygusal zekâlari ile prenatal bağlanma düzeyleri arasindaki ilişki. Anadolu Hemşirelik ve Sağlık Bilimleri Dergisi 2016; 19: 217-24.

24. Elkin N. Gebelerin prenatal bağlanma düzeyleri ve bunları etkileyen faktörler. Sürekli Tıp Eğitimi Dergisi 2015; 24: 230-6.

25. Tani F, Castagna V, Ponti L. Women who had positive relationships with their own mothers reported good attachments to their first child before and after birth. Acta Paediatrica 2018; 107: 633-7. [CrossRef]

26. Harpel TS, Barras KG. The Impact of Ultrasound on Prenatal Attachment Among Disembodied and Embodied Knowers. Journal of Family Issues 2018; 39: 1523-44.
27. Busonera A, Cataudella S, Lampis J, Tommasi M, Zavattini GC. Prenatal Attachment Inventory: expanding the reliability and validity evidence using a sample of Italian women. Journal of Reproductive and Infant Psychology 2017; 35: 462-79. [CrossRef]

28. Molgora S, Acquati C, Fenaroli V, Saita E. Dyadic coping and marital adjustment during pregnancy: A cross-sectional study of Italian couples expecting their first child. International Journal of Psychology 2018. [CrossRef]

29. Rollè L, Prino LE, Sechi C, Vismara L, Neri E, Polizzi C, et al. Parenting Stress, Mental Health, Dyadic Adjustment: A Structural Equation Model. Frontiers in Psychology 2017; 8: 1-10. [CrossRef]

30. Güneş $M$, Selcuk H, Demir S, İbiloğlu AO, Bulut $M$, Kaya MC, et al. Çocuk Evliliği Yapan Kadınlarda Çift Uyumu ve Çocukluk Çağı Ruhsal Travması. Journal of Mood Disorders 2016; 6: 63-70. [CrossRef]

31. Akkaş SÇ. Gebelik döneminde eşler arası uyum. Adnan Menderes Üniversitesi Sağlık Bilimleri Enstitüsü Doğum-Kadın Sağlığı ve Hastalıkları Hemşireliği Anabilim Dalı (Yüksek Lisans Tezi). Aydın, 2014.

32. Nacar G, Taşhan ST, Döner F, Gürsoy B, Çavdar L, Gündoğan S, Apaki D. Gebelikte çift uyumunun prenatal bağlanma üzerine etkisi. I. Uluslararası ve II. Ulusal Kadın Sağılığı Hemşireliği Kongresi, 23-24 Mart 2018, İstanbul. (Sözel Sunum OP-162).

33. Cox MJ, Owen MT, Lewis JM, Henderso VK. Child Development. 1989; 60; 1015-24. [CrossRef]

34. Mazzeschi C, Pazzagli C, Radi G, Raspa V, \& Buratta L. Antecedents of maternal parenting stress: the role of attachment style, prenatal attachment, and dyadic adjustment in first-time mothers. Frontiers in psychology 2015;6,:1443. [CrossRef]

35. Tunçel NT, Süt HK. Gebelikte yaşanan anksiyete, depresyon ve prenatal distres düzeyinin doğum öncesi bağlanmaya etkisi. Kadın Sağlığı Hemşireliği Dergisi 2018; 1: 70.

36. Durualp E, Kaytez N, Girgin BA. Evlilik doyumu ve maternal baglanma arasindaki iliskinin incelenmesi/An analysis of the relation between marital satisfaction and maternal bonding. Anadolu Psikiyatri Dergisi 2017; 18: 129. [CrossRef]

37. Güney $E$, Uçar T. Effect of the fetal movement count on maternalfetal attachment. Japan Journal of Nursing Science 2018. [CrossRef]

38. Malm MC, Hildingsson I, Rubertsson C, Rådestad I, Lindgren $\mathrm{H}$. Prenatal attachment and its association with foetal movement during pregnancy-A population based survey. Women and Birth 2016; 29: 482-6. [CrossRef]

39. Ossa X, Bustos L, Fernandez L. Prenatal attachment and associated factors during the third trimester of pregnancy in temuco. Chili Midwifery 2011; 28: 689-96. [CrossRef]

40. Metin A. Gebelerin Algıladıkları Sosyal Destek Ile Prenatal Bağlanma Arasındaki İlişki. Atatürk Üniversitesi Sağlık Bilimleri Enstitüsü (Yüksek Lisans Tezi). Erzurum, 2014.

41. Hergüner S, Çiçek E, Annagür A, Hergüner A, Örs R. Doğum şeklinin doğum sonrası depresyon, algılanan sosyal destek ve maternal bağlanma ile ilişkisi. Düşünen Adam: Psikiyatri ve Nörolojik Bilimler Dergisi 2014; 27: 15-20. [CrossRef]

42. Aksoy YE, Yılmaz SD, Aslantekin F. Riskli gebeliklerde prenatal bağlanma ve sosyal destek. Turkiye Klinikleri Journal of Health Sciences 2016;1:163-9. [CrossRef]

43. Yekenkunrul D. Gebelikte bulantı kusma, evlilik uyumu ve eş ilişkisi arasındaki ilişkinin incelenmesi. Dokuz Eylül Üniversitesi Sağlık Bilimleri Enstitüsü Doğum-Kadın Sağlığı ve Hastalıkları Hemşireliği Anabilim Dalı (Doktora Lisans Tezi). İzmir, 2011. 